\title{
Projeto de sistemas de produção na construção civil empregando simulação no apoio à tomada de decisão
}

\author{
Production system design in construction using simulation \\ to support decision-making
}

\section{Fábio Kellermann Schramm Carlos Torres Formoso}

\section{Resumo \\ $\mathbf{E}$} ste trabalho propõe um modelo para projetar sistemas de produção de empreendimentos da construção, utilizando simulação de eventos discretos no apoio à tomada de decisões, tendo como ponto de partida um modelo anteriormente proposto. A Pesquisa Construtiva, caracterizada pela implementação de construções inovadoras para a solução de classes de problemas com relevância prática, foi a abordagem metodológica utilizada. O trabalho foi dividido em quatro fases: (a) revisão de literatura; (b) fase exploratória, em que ocorreu a seleção do software de simulação e um estudo exploratório; (c) fase de desenvolvimento, na qual foram realizados quatro estudos empíricos para o desenvolvimento e avaliação do modelo proposto; e (d) fase de análise e reflexão, na qual foi discutido o papel do Projeto do Sistema de Produção e os principais benefícios e dificuldades do emprego da simulação no apoio a esse processo. Uma estratégia de reutilização de modelos foi proposta como forma de reduzir o tempo de desenvolvimento dos modelos de simulação. $\mathrm{O}$ modelo proposto divide o PSP em duas fases interdependentes: a fase determinística e a fase dinâmica, na qual são desenvolvidos os modelos de simulação e testados cenários para apoiar a tomada de decisão.

Palavras-chave: Projeto do sistema de produção. Simulação de eventos discretos. Gestão da construção.

\section{Abstract}

This research study proposes a model for designing the production systems of construction projects based on the use of discrete event simulation as a tool to support decision-making, using as a starting point a previously developed model. Constructive research was the methodological approach adopted in this study, in which innovative construction projects are devised in order to solve different types of relevant practical problems. The study was divided into four phases: (a) literature review; (b) exploratory phase, in which a simulation software was selected and an exploratory study was carried out;

Fábio Kellermann Schramm Universidade Federal de Pelotas Pelotas - RS - Brasil

Carlos Torres Formoso Universidade Federal do Rio Grande Porto Alegre - RS - Brasil

Recebido em 01/03/15 Aceito em 25/06/15 (c) development phase, which involved four empirical studies, in which the proposed model was devised and evaluated; and (d) analysis and reflection phase, in which the role of production system design was analysed, as well the main benefits and difficulties of using simulation to design production systems. A strategy for reusing models was also proposed in order to reduce the duration of the simulation models. The proposed model for Production System Design has two overlapping phases: a deterministic phase and a dynamic phase, in which simulation models are developed and scenarios are tested to support decision-making.

Keywords: Production system design. Discrete event simulation. Construction management. 


\section{Introdução}

O projeto do sistema de produção (PSP) representa uma das primeiras tarefas gerenciais a ser realizadas em qualquer esforço produtivo (BALLARD et al., 2001), consistindo na primeira oportunidade para combater ou atenuar características negativas inerentes aos sistemas de produção, como a variabilidade (KOSKELA, 2000).

No caso da construção civil, o PSP geralmente recebe pouca atenção, tanto pela comunidade acadêmica como pelo meio profissional. Do ponto de vista acadêmico, relativamente pouco ainda tem sido publicado a respeito do PSP na construção civil. Entre os autores que abordam temas referentes ao PSP, alguns versam especificamente sobre o tema (HOWELL; BALLARD, 1999; BALLARD et al., 2001), enquanto outros versam sobre decisões que, de forma isolada ou em conjunto, são pertinentes a seu escopo (MENDES JUNIOR; HEINECK, 1998; SAFFARO; PAULA, 2002).

Paradoxalmente, há quase quatro décadas, Halpin e Woodhead (1976) apontaram essa deficiência, afirmando que tradicionalmente as decisões que formam o escopo do PSP não são consideradas antecipadamente, mas deixadas a cargo do pessoal operacional durante a fase de execução.

Entretanto, do ponto de vista prático, para que se possa desenvolver um projeto do sistema de produção, qualquer que seja o setor produtivo, deve-se considerar alguns fatores que caracterizam a natureza dos sistemas de produção e que contribuem para o aumento de sua complexidade, como a variabilidade, a incerteza, a interdependência e a interconectividade (GIDADO, 1996; ROBINSON, 2003).

Entre as várias técnicas disponíveis, a simulação permite avaliar o comportamento dos sistemas de produção, considerando todos os fatores que condicionam seu comportamento, uma vez que utiliza um amplo conjunto de métodos e ferramentas visando reproduzir o comportamento de sistemas reais, usualmente em computador e com um software apropriado (KELTON; SADOWSKI; STURROCK, 2004).

Em geral, os estudos aplicando simulação de eventos discretos (SED) na construção civil têm focado operações ou processos considerados de forma isolada. Pouco tem sido escrito sobre seu uso para projetar sistemas de produção, e até agora esses estudos têm utilizado a SED para testar proposições em sistemas teóricos (DRAPER; MARTINEZ, 2002) ou em sistemas reais, mas em análises do tipo ex post (ALVES; TOMMELEIN; BALLARD, 2006).

Entre os principais motivos para o ainda parco uso da SED na gestão de sistemas de produção na construção, pode-se apontar:

(a) a complexidade dos processos e consequentemente de sua modelagem (OLOUFA; IKEDA; NGUYEN, 1998; SANTOS, 2001);

(b) o aumento no tempo de elaboração dos modelos, em função dessa complexidade (SHI; ABOURIZK, 1997);

(c) a necessidade de um usuário bem preparado para a condução dos experimentos (SHI; ZHANG, 1999); e

(d) o modelo de simulação, frequentemente percebido como uma "caixa-preta", o que dificulta seu entendimento e acreditação por parte dos usuários (SHI; ZHANG, 1999).

Assim, o objetivo deste trabalho consiste em propor um modelo para a elaboração do PSP de empreendimentos da construção civil considerando a utilização da simulação de eventos discretos como ferramenta de apoio à tomada de decisão.

Tomando-se como ponto de partida o modelo para elaboração do PSP proposto por Schramm (2004), busca-se ainda:

(a) avaliar o emprego da simulação de eventos discretos na elaboração do PSP na construção, tendo em vista suas características peculiares; e

(b) propor e avaliar a adoção da estratégia de reutilização de modelos de simulação como forma de reduzir o tempo de desenvolvimento do PSP.

\section{Modelo de elaboração do projeto do sistema de produção}

O projeto do sistema de produção é uma atividade gerencial que deve ser realizada antecipadamente em relação ao início das atividades de produção. Segundo Koskela (2001), o PSP representa a solução mais básica para a redução de fatores que impactam negativamente os sistemas produtivos (como a variabilidade e a incerteza, por exemplo). Quanto maior a antecipação temporal dessa etapa, maiores as oportunidades para a inserção de medidas que contribuam para a redução da parcela de atividades que não agregam valor ao sistema de produção sob consideração (SCHRAMM; COSTA; FORMOSO, 2006). 
De forma sucinta, o escopo de decisões do modelo é definido com base em uma série de seis etapas, agrupadas de acordo com a unidade de análise a que se referem: a unidade-base ou o empreendimento como um todo. Já as etapas propostas devem ser percebidas de forma integrada ou holística, uma vez que a modificação de uma das decisões estabelecidas repercutirá, em maior ou menor grau, nas demais, a jusante ou a montante da etapa em questão. Dessa forma, há setas em dois sentidos, uma no sentido do fluxo de decisão, caracterizado pela definição da etapa, e a outra no sentido do fluxo de revisão, necessário em função do aspecto iterativo do processo.

Posteriormente, Rodrigues (2006) propôs, com base no modelo de Schramm (2004), sua adaptação ao contexto de empreendimentos complexos da construção civil.

Schramm (2004) identificou a necessidade de aprofundamento dos estudos relacionados ao PSP, de forma a utilizar técnicas de modelagem e simulação de sistemas de produção, permitindo a visualização e interação com os usuários, na geração e discussão de alternativas de organização do sistema de produção, além de avaliar os impactos da variabilidade dos processos de produção, empregando dados estocásticos, ao invés de determinísticos, como no modelo original.

Schramm (2004) propôs um modelo para elaboração do projeto do sistema de produção para empreendimentos habitacionais de interesse social
(EHIS), Figura 1, empreendimentos que podem ser caracterizados pela repetitividade dos processos, demanda perfeitamente definida no início da produção, lead time curto, ou seja, necessidade de rapidez na execução, além do número relativamente alto de unidades.

\section{Modelagem e simulação de sistemas de produção na construção civil}

Shi e AbouRizk (1998) reiteram o potencial do emprego da simulação de eventos discretos (SED) na gestão de empreendimentos da construção, mas chamam a atenção para a necessidade de estudos que busquem torná-la uma ferramenta de utilização mais ampla no setor, principalmente reduzindo o tempo de desenvolvimento dos modelos $\mathrm{e}$ tornando a simulação mais amigável ao usuário. Nesse sentido, os mesmos autores apontam duas estratégias: a de modelagem e simulação empregando elementos gráficos e de visualização; e a de reutilização dos modelos de simulação.

\section{Simulação interativa visual}

Elementos gráficos na modelagem e simulação de sistemas foram conceitos propostos inicialmente por Hurrion (1976), com o objetivo de facilitar esse processo, além de permitir a interação do usuário.

Figura 1 - Etapas da elaboração do PSP para EHIS

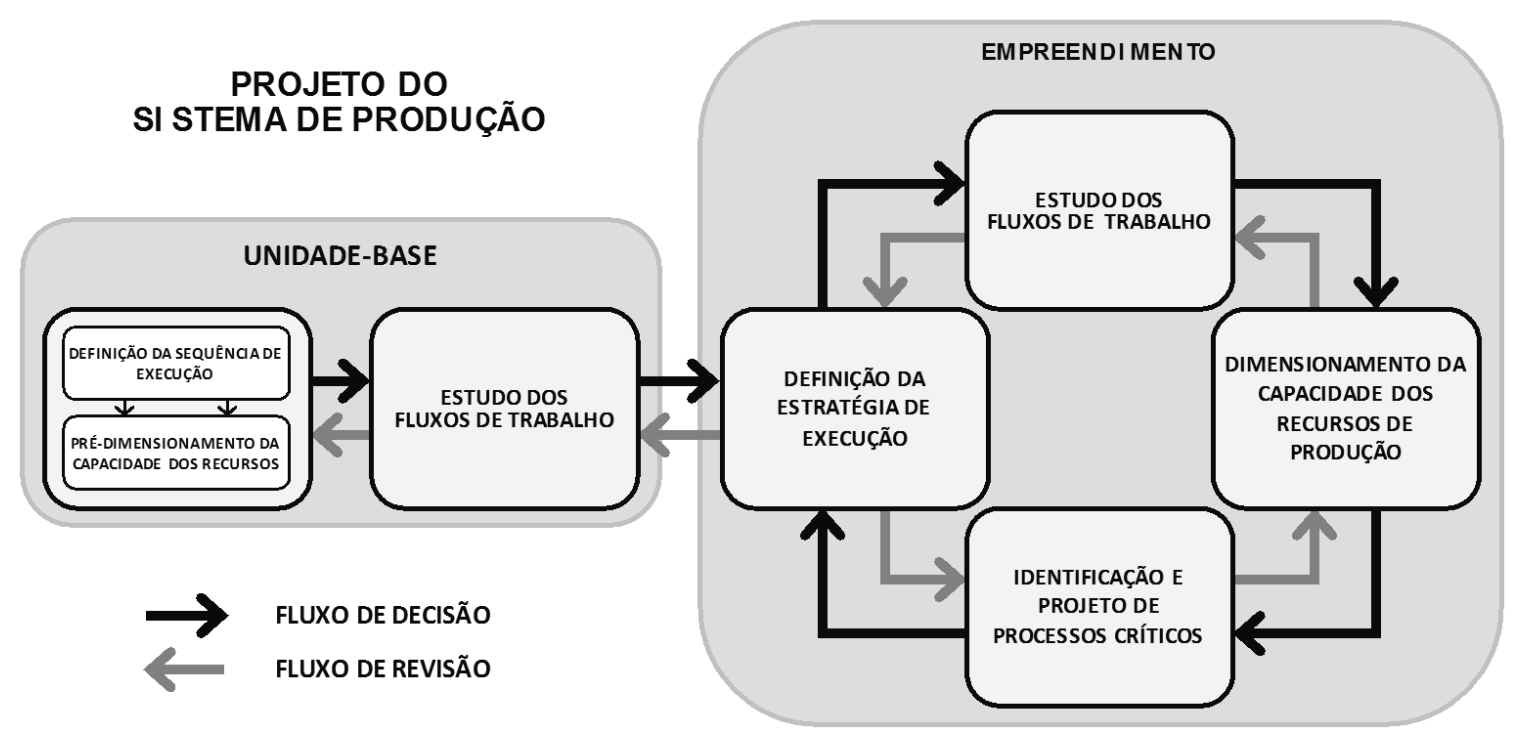

Fonte: Schramm (2004). 
Algumas vantagens dessa estratégia são:

(a) o estímulo a criatividade e insights, promovendo um processo de "gerar e testar", que facilita um ciclo rápido de aprendizagem (BELTON; ELDER, 1991);

(b) a contribuição para tornar um modelo de simulação mais transparente, permitindo ao usuário visualizar as interações dinâmicas durante o processo de simulação (SHI; ZHANG, 1999); e

(c) a simplificação do processo de modelagem através das interfaces gráficas, permitindo ao usuário ver e manipular o modelo sem ter de editar representações textuais (HAJJAR; ABOURIZK, 2002).

No setor da construção civil, a utilização da modelagem gráfica, ou modelagem visual aplicada à construção civil, há algum tempo é reportada por alguns autores (OLOUFA; IKEDA; NGUYEN, 1998; HONG; SHI; TAM, 2002; NASEREDDIN; MULLENS; COPE, 2007).

\section{Reutilização de modelos}

Segundo Oloufa, Ikeda e Nguyen (1998), o tempo necessário para o desenvolvimento do modelo de simulação está entre as razões que limitam sua efetiva implementação na gestão da construção, uma vez que em setores industriais nos quais as atividades de produção são perenes o investimento de tempo no desenvolvimento dos modelos pode ser compensador.

Já na construção civil, devido à natureza temporária dos sistemas produtivos e à presença de incerteza, torna-se necessário obter respostas rapidamente, reduzindo o tempo disponível para o desenvolvimento dos modelos (OLOUFA; IKEDA; NGUYEN, 1998).

Uma estratégia para redução do tempo de desenvolvimento dos modelos de simulação consiste no emprego de modelos genéricos e reutilizáveis (MACKULAK; LAWRENCE; COLVIN, 1998; OLOUFA; IKEDA; NGUYEN, 1998; NASEREDDIN; MULLENS; COPE, 2007).

Segundo Robinson (2003), um modelo genérico é aquele construído para um contexto particular, que pode ser utilizado em várias organizações. Esses modelos são geralmente muito focados, abordando somente alguns aspectos específicos do problema sob estudo (ROBINSON, 2003).

Ainda conforme Robinson (2003), um modelo reutilizável implica utilizar um modelo completo em outro contexto ou para propósito diferente daquele originalmente proposto. Já o conceito de componente reutilizável envolve o emprego de uma parte do modelo em um novo modelo de simulação em contexto distinto ou para outro propósito (ROBINSON, 2003).

A reutilização de modelos é especialmente útil quando são modelados sistemas de um mesmo domínio ou setor, pois, conforme Mukkamala, Smith e Valenzuela (2003), nesses casos o processo de modelagem caracteriza-se pela repetitividade, e os modelos passam a ser similares em vários aspectos, apresentando somente pequenas diferenças. Assim, o esforço de modelagem pode ser reduzido através do desenvolvimento de módulos ou modelos-padrão, que condensem a lógica e a maioria dos detalhes de modelagem (MUKKAMALA; SMITH; VALENZUELA, 2003).

\section{Método de pesquisa}

Optou-se pela pesquisa construtiva (Constructive Research) como abordagem metodológica para esta pesquisa, que é, segundo Lukka (2003), um procedimento de pesquisa para produzir "construções inovadoras", com o intuito de resolver classes de problemas reais e contribuir para a teoria na disciplina na qual é aplicada.

Segundo Lukka (2003), há dois tipos principais de contribuições teóricas potenciais:

(a) a própria construção desenvolvida, com base em sua utilidade para a organização-alvo, representando uma contribuição ao conjunto do conhecimento até então existente; e

(b) a aplicação e desenvolvimento do conhecimento teórico existente durante a realização do estudo, através da compreensão holística das relações entre conceitos.

\section{Delineamento da pesquisa}

A pesquisa foi dividida em quatro fases (Figura 2):

(a) revisão bibliográfica, desenvolvida ao longo de todo o trabalho;

(b) fase exploratória;

(c) fase de desenvolvimento; e

(d) fase de análise e reflexão.

Essas fases guardam relação com as etapas da pesquisa construtiva sugeridas por Lukka $\left(2000^{1}\right.$ apud LUKKA, 2003), que estão apresentadas na parte superior da Figura 2.

A primeira fase da pesquisa envolveu uma revisão bibliográfica inicial e também a busca de um

\footnotetext{
${ }^{1}$ LUKKA, K. The key issues of applying the constructive approach to field research. In: REPONEN, T. (Ed.). Management expertise for the new millennium. Turku: Turku School of Economics and Business Administration, 2000. Series A-1.
} 
problema real junto à indústria. A primeira etapa da pesquisa construtiva - encontrar um problema com relevância prática - correspondeu às sugestões apontadas nas pesquisas anteriormente realizadas, servindo de base para a definição do problema de pesquisa.

A pesquisa bibliográfica e a fase exploratória do trabalho, na qual foi realizada a seleção do software de simulação, o treinamento em sua utilização, além da realização de um estudo exploratório que teve como principal objetivo familiarizar $\mathrm{o}$ pesquisador com o software escolhido para o desenvolvimento do modelo de simulação no contexto da construção civil e da compreensão de possíveis limitações e abstrações necessárias no processo de modelagem, contemplaram a segunda etapa da pesquisa construtiva - obter um entendimento profundo sobre o tema.

Com base na ponderação dos critérios facilidade de uso, adequação ao contexto da pesquisa, qualidade dos recursos de animação e capacidades estatísticas, optou-se pela utilização do software Rockwell Arena ${ }^{\circledR}$ para o desenvolvimento dos estudos deste trabalho. A Figura 3, a seguir, apresenta a interface do referido software, bem como dá uma visão geral de um dos modelos de simulação desenvolvidos.

A fase de desenvolvimento consistiu na realização de quatro estudos de caso, correspondendo às etapas 3 e 4 da pesquisa construtiva - desenvolver uma construção para resolver o problema e implementar e testar a solução respectivamente. É importante ressaltar que o desenvolvimento da construção (modelo de PSP proposto neste trabalho) emergiu ao longo da realização dos quatro estudos de caso, e não a priori.

Os estudos EC1 e EC2 foram desenvolvidos em empreendimentos da empresa X (X1 e X2), enquanto os estudos EC3 e EC4 foram desenvolvidos em empreendimentos da empresa Y (Y1 e Y2). O Quadro 1, a seguir, resume os estudos de caso realizados, quanto a seus objetivos, empresas e empreendimentos estudados.

Todos os estudos trataram da elaboração do PSP, considerando o escopo e sequência de decisões propostos por Schramm (2004). Quanto ao uso da simulação de eventos discretos, tendo em vista os objetivos apresentados no Quadro 1, o Quadro 2, de forma resumida, apresenta as atividades realizadas em cada estudo de caso, bem como suas principais peculiaridades, no que concerne a seu emprego.

A quinta etapa da pesquisa construtiva - examinar o escopo de aplicabilidade da solução - foi realizada de duas formas:

(a) na primeira, cada caso foi analisado separadamente (within-case analysis); e

(b) na segunda etapa foi feita uma comparação dos vários casos entre si (cross-case analysis), buscando similaridades e diferenças entre eles que facilitassem a obtenção de conclusões a respeito do objeto de estudo.

Figura 2 - Delineamento da pesquisa

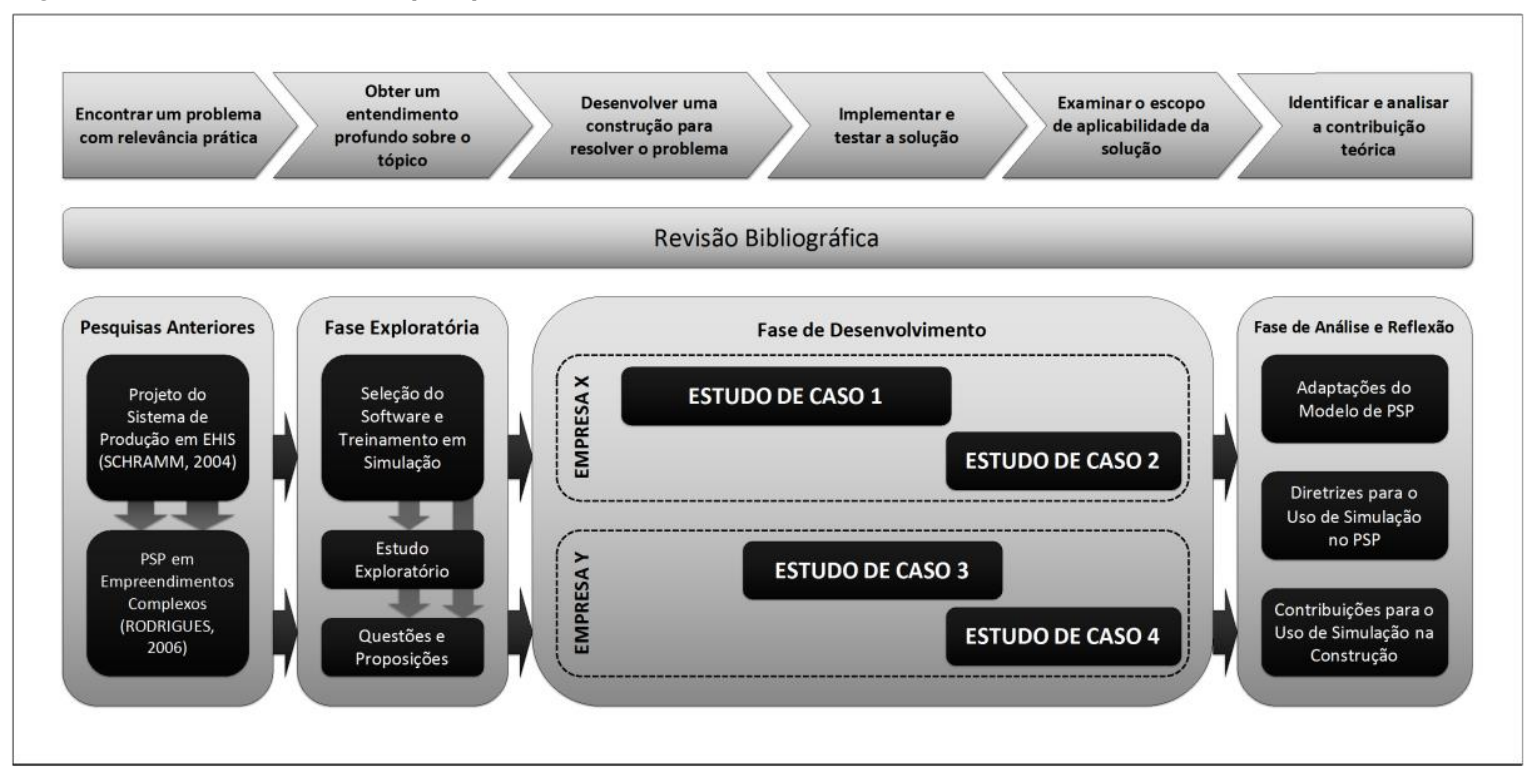


Figura 3 - Interface do software de simulação e visão geral de um modelo de simulação desenvolvido

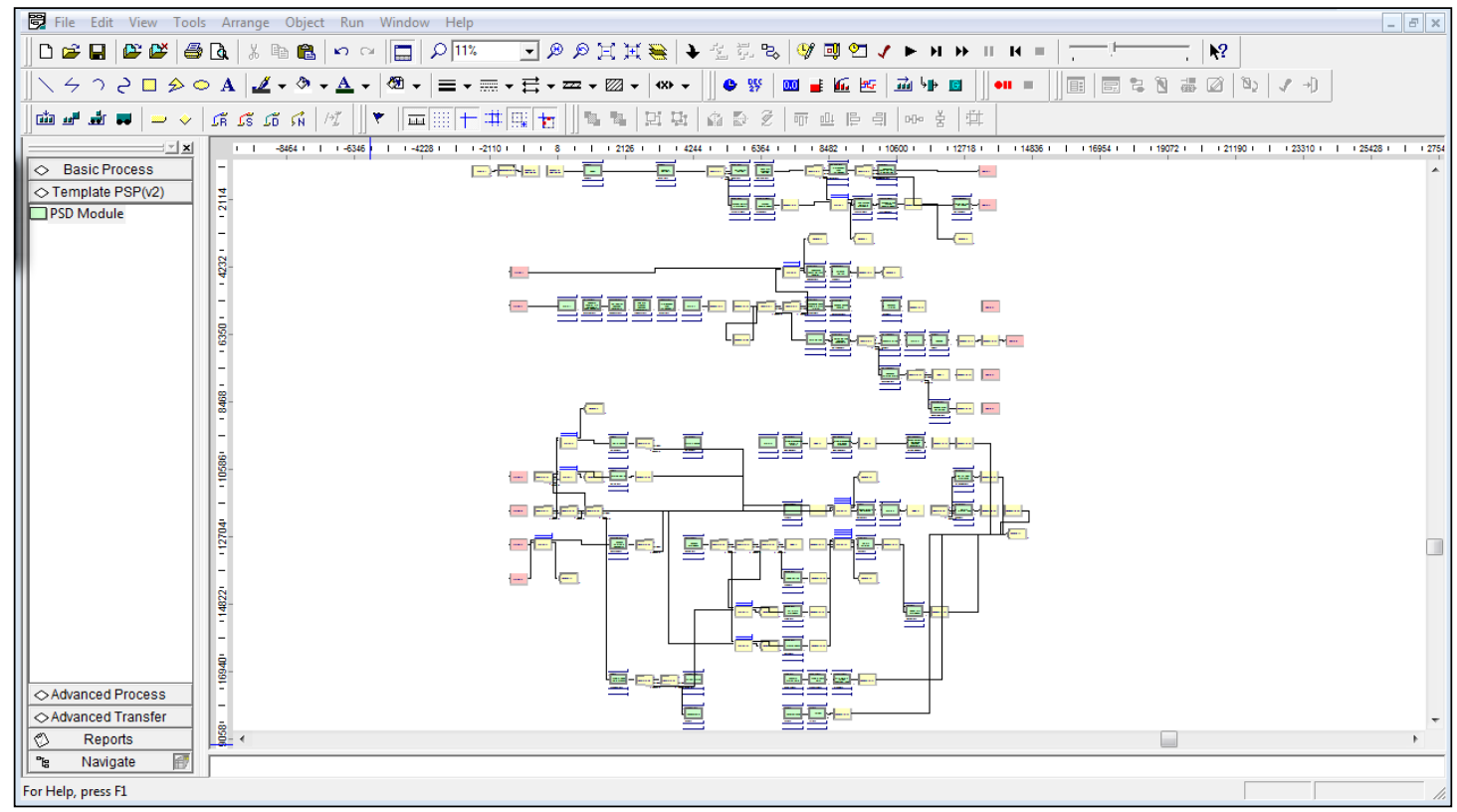

Quadro 1 - Resumos dos estudos de caso desenvolvidos

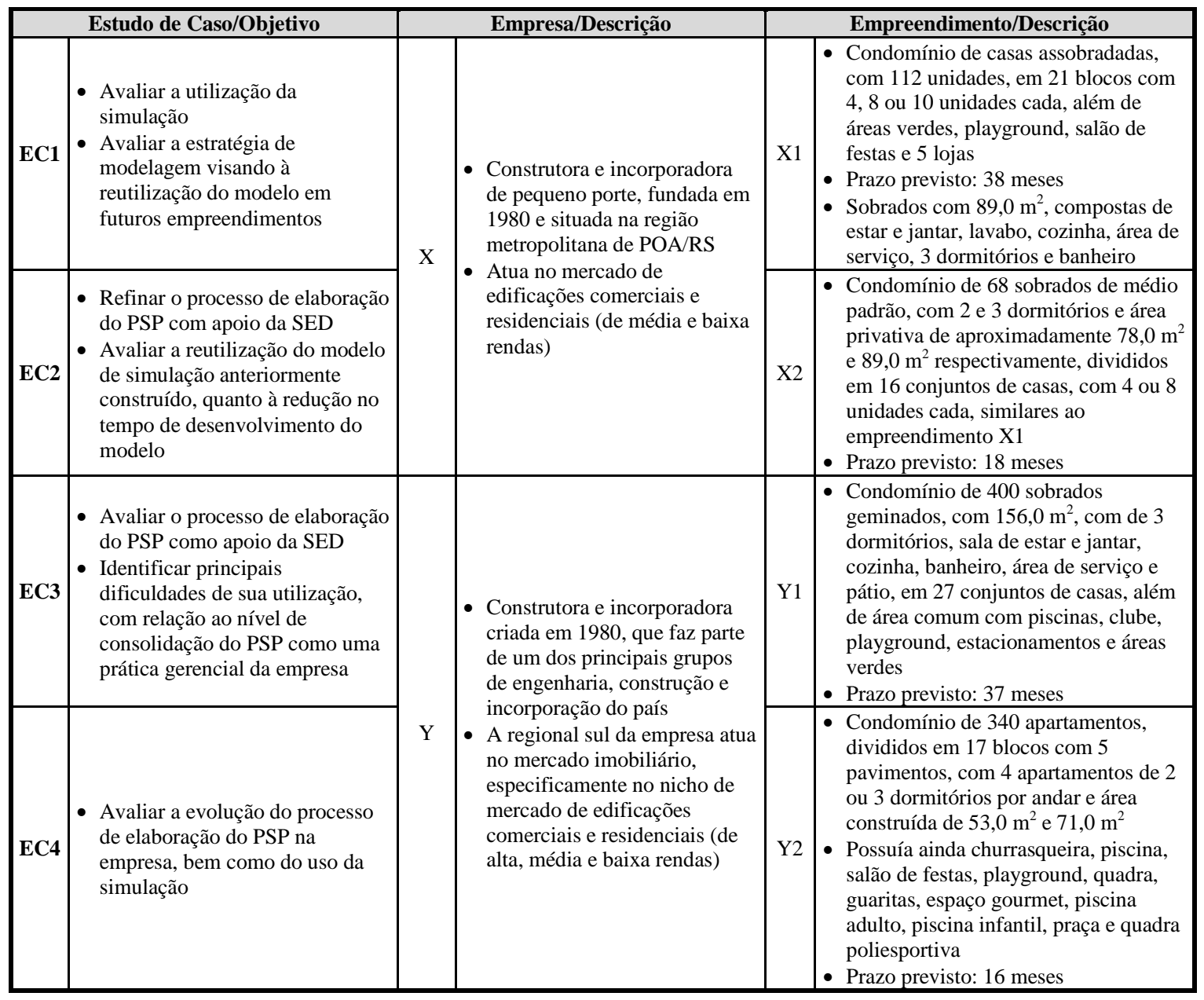

170 Schramm, F. K.; Formoso, C. T. 
Quadro 2 - Emprego da simulação de eventos discretos nos estudos de caso desenvolvidos

\begin{tabular}{|c|c|c|c|c|}
\hline Estudo & $\begin{array}{c}\text { Modelos } \\
\text { Elaborados }\end{array}$ & $\begin{array}{c}\text { Cenários } \\
\text { Testados }\end{array}$ & \multicolumn{1}{|c|}{ Foco da Simulação } & \multicolumn{1}{c|}{ Comentários } \\
\hline EC1 & 01 & 05 & $\begin{array}{l}\text { Avaliação de opçães de programação } \\
\text { detalhada da obra, verificando seus } \\
\text { impactos em termos de lead times de } \\
\text { execução dos blocos e do } \\
\text { empreendimento }\end{array}$ & $\begin{array}{l}\text { - Pequeno número de cenários por dois } \\
\text { motivos: } \\
\text { a. primeira experiência de uso da } \\
\text { simulação no PSP por parte do } \\
\text { pesquisador e da empresa } \\
\text { b. prolongado tempo de desenvolvimento } \\
\text { do estudo, estendendo-se ao longo da } \\
\text { fase de execução }\end{array}$ \\
\hline EC2 & 01 & 17 & $\begin{array}{l}\text { - Avaliação das estratégias de ataque } \\
\text { de alguns processos, número de } \\
\text { equipes e alocação de atividades a } \\
\text { elas } \\
\text { remandas surgidas ao longo das }\end{array}$ & $\begin{array}{l}\text { - A equipe da empresa utilizou a simulação } \\
\text { como uma forma de explorar o sistema de } \\
\text { produção do empreendimento } \\
\text { Maior ênfase na simulação, pois o modelo } \\
\text { foi empregado com mais antecedência em } \\
\text { relação ao início do empreendimento, } \\
\text { viabilizado pela estratégia de reutilização } \\
\text { do modelo }\end{array}$ \\
\hline EC3 & 01 & 01 & $\begin{array}{l}\text { - Avaliação das datas de conclusão das } \\
\text { fases do empreendimento ante o } \\
\text { aumento das frentes de trabalho }\end{array}$ & $\begin{array}{l}\text { A equipe da empresa não participou do } \\
\text { processo de desenvolvimento do modelo, } \\
\text { apenas da validação e da definição de } \\
\text { cenários }\end{array}$ \\
\hline EC4 & 02 & 03 & $\begin{array}{l}\text { Simulação de processos críticos } \\
\text { quanto ao número de frentes de } \\
\text { trabalho e seus impactos em prazo }\end{array}$ & $\begin{array}{l}\text { - Houve distanciamento da equipe da } \\
\text { empresa quanto ao uso da simulação }\end{array}$ \\
\hline
\end{tabular}

Buscou-se estabelecer critérios que permitissem avaliar o processo tendo como premissa a utilização de múltiplas fontes de evidência, como forma de reforçar a consistência da análise dos dados.

Para tanto, dois constructos foram identificados e utilizados neste trabalho:
(a) utilidade; e
(b) facilidade de uso.

Por se tratar de constructos amplos e de difícil mensuração, foram desdobrados em subconstructos (Quadro 3), que permitiram a avaliação através de evidências ou variáveis.

Um conjunto de técnicas de coleta e análise de dados foi empregado como forma de compor as evidências necessárias à análise, tais como observação direta, observação participante, análise documental e entrevistas.

Por fim, a sexta etapa da pesquisa construtiva identificar e analisar a contribuição teórica - diz respeito à reflexão e discussão dos resultados alcançados neste trabalho, apresentados a seguir, tendo como base as avaliações que utilizaram os constructos e subconstructos apresentados anteriormente.

\section{Avaliação do emprego da simulação na elaboração do PSP}

\section{Nível de detalhamento dos modelos}

De forma geral, os sistemas de produção foram modelados em um maior nível de detalhamento, buscando aproximar os modelos das características reais ou pretendidas para os sistemas de produção sob estudo.

Nos estudos EC1 e EC2, em função da experiência em empreendimentos similares, foram utilizados modelos de simulação mais detalhados, como forma de conhecer mais profundamente os efeitos que algumas decisões em um nível operacional poderiam ter sobre o comportamento do sistema de produção.

No EC1, por exemplo, tendo como base a análise dos resultados da primeira simulação realizada (cenário A), a avaliação dos dados relativos ao número de mobilizações ${ }^{2}$ e nível de utilização das equipes (Figura 4) redundou na simulação de um cenário com o aumento do número de equipes de eletricistas (maior número de mobilizações e alto nível de utilização) de uma (cenário A, plano original) para sete equipes (cenário B), tendo como parâmetro de comparação os prazos médios de conclusão (em dias úteis) dos 10 últimos conjuntos de casas que formavam o empreendimento.

Com base na comparação desses cenários (Tabela 1), o aumento no número de equipes de eletricistas possibilitava a redução de aproximadamente 116 
dias úteis no prazo médio do empreendimento ($25,9 \%$ ), bem como a redução nos prazos individuais dos conjuntos de casas, possibilitando uma antecipação em relação ao cenário original (com uma única equipe de eletricistas), fruto do aumento seletivo da capacidade dos recursos de produção.
Embora mais adequados para a tomada de decisão no contexto dos estudos realizados, o emprego de modelos mais detalhados apresenta algumas desvantagens.

Primeiro, o maior detalhamento dos modelos afeta o esforço e o tempo requeridos para o desenvolvimento, como foi o caso nos estudos EC1 e EC4.

Quadro 3 - Constructos e subconstructos utilizados

\begin{tabular}{|l|l|}
\hline \multicolumn{1}{|c|}{ Constructos } & \multicolumn{1}{c|}{ Subconstructos } \\
\hline \multirow{3}{*}{ Utilidade } & $\begin{array}{l}\text { - Contribuição do PSP para a percepção de tomada de decisão de forma conectada } \\
\text { - Utilização do PSP como referência na tomada de decisão }\end{array}$ \\
& $\begin{array}{l}\text { - Contribuição para a sistematização do processo de tomada de decisão } \\
\text { - Contribuição do emprego da SED para o processo de tomada de decisão do PSP }\end{array}$ \\
\hline \multirow{3}{*}{ Facilidade de uSo } & $\begin{array}{l}\text { - Iniciativa dos participantes no processo de modelagem } \\
\text { - Extensão do processo de elaboração do PSP }\end{array}$ \\
& $\begin{array}{l}\text { - Contribuição para a comunicação e o entendimento das decisões entre os participantes } \\
\text { - Possibilidade de continuação do processo após o estudo }\end{array}$ \\
\hline
\end{tabular}

Figura 4 - Número de mobilizações (esquerda) e nível de utilização (direita) das equipes do empreendimento X1 (EC1)
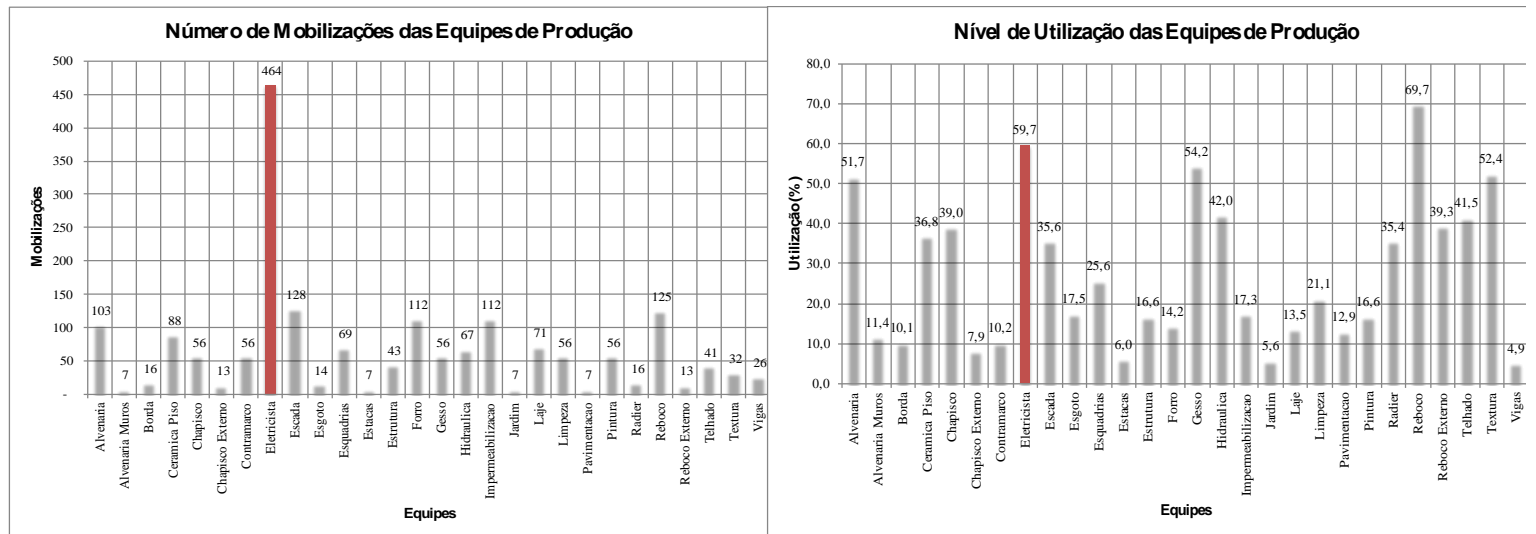

Tabela 1 - Prazos médios de conclusão (em dias úteis) para os cenários simulados (30 replicações) ${ }^{2}$

\begin{tabular}{ccccc}
\hline \multirow{2}{*}{ Conjunto } & \multicolumn{2}{c}{ Cenário A: 1 equipe } & \multicolumn{2}{c}{ Cenário B: 7 equipes } \\
\cline { 2 - 5 } & Prazo médio & Desvio padrão & Prazo médio & Desvio padrão \\
\hline 1 & 106,1 & 2,2 & 101,0 & 2,1 \\
2 & 163,2 & 2,5 & 130,5 & 3,9 \\
3 & 168,0 & 2,6 & 144,8 & 3,6 \\
4 & 220,3 & 2,6 & 167,9 & 4,8 \\
5 & 225,0 & 2,6 & 180,4 & 4,4 \\
6 & 274,4 & 3,0 & 203,9 & 3,9 \\
7 & 279,1 & 3,0 & 216,8 & 3,3 \\
8 & 331,3 & 2,5 & 253,6 & 4,7 \\
9 & 385,7 & 2,5 & 294,6 & 6,6 \\
10 & 444,2 & 3,4 & 328,4 & 4,8 \\
\hline
\end{tabular}

\footnotetext{
${ }^{2}$ A mobilização de uma equipe significa quantas vezes ela se desloca a uma unidade habitacional específica a fim de executar uma atividade. Quanto maior o número de mobilizações de uma equipe, maior é a probabilidade de que ela possa ser deslocada para a execução de uma unidade habitacional que não é prioritária na sequência de execução do empreendimento para que não fique ociosa.
} 
Segundo, o tempo necessário para que cada cenário seja simulado também aumenta, dificultando a utilização da simulação durante as reuniões do PSP. Nos estudos EC1 e EC2, cada cenário simulado demandava em torno de $20 \mathrm{~min}$ para sua consecução, possibilitando que muitos cenários fossem propostos e simulados ao longo das reuniões com a equipe da empresa, enquanto no estudo EC4 o modelo demandava em torno de 6 h para o teste de cada cenário.

Terceiro, com um maior nível de detalhamento, qualquer pequena modificação na configuração do sistema de produção requer a respectiva atualização do modelo, demandando algum tempo para a realização da modificação e posterior verificação do modelo resultante.

Por sua vez, modelos mais simples permitem demonstrar os efeitos da aplicação de conceitos de gestão da produção mais diretamente. Isso pode ser percebido no estudo EC4, no qual o modelo construído para os processos críticos (elevação de alvenaria e montagem de lajes) permitiu que fossem mostrados os efeitos da variabilidade e da sincronização dos processos nos fluxos de trabalho e do aumento do número de frentes de trabalho nos lead times desses processos.

\section{Apoio da visualização ao processo de simulação}

Este trabalho propôs a integração da linha de balanço (line of balance - LOB) como uma ferramenta de visualização dos resultados da simulação. As principais vantagens dessa integração é que a linha de balanço registra os fluxos de trabalho e do produto ao longo do tempo, auxiliando a verificação e a validação do modelo, bem como a análise dos efeitos de mudanças propostas no sistema de produção de forma mais transparente. Dessa forma, procurou-se valorizar a análise dos resultados da simulação sob o ponto de vista das atividades de transformação, e, sobretudo, das atividades de fluxo.

Entretanto, embora apresentando vantagens, o emprego da visualização nos estudos de caso foi limitado. Embora o software utilizado para simulação permitisse a visualização do processo em tempo real, seus recursos nesse sentido eram bastante limitados em função do nível de compreensão dos participantes e do número de entidades e processos presentes nos modelos (função do nível de detalhamento empregado). O apoio da linha de balanço, por sua vez, também foi limitado pelo número de processos representados. Para contornar esse problema, algumas vezes foram geradas linhas de balanço nas quais apenas os processos considerados críticos eram representados, de forma a tornar a avaliação dos dados mais objetiva e simples.

\section{Reutilização de modelos}

Durante a realização do EC1, como forma de tentar reduzir o tempo necessário para o desenvolvimento do modelo e possibilitar sua utilização no decorrer do estudo o mais precocemente possível, propôs-se a construção de um módulo de simulação que sumarizasse genericamente as características de um processo produtivo e que pudesse ser rapidamente configurado a partir da entrada de dados.

Este "módulo genérico" deveria, ainda, fornecer uma interface para a coleta de dados do processamento de cada entidade (unidade-base) por ele processada (início e fim do processamento, por exemplo). Assim, com base nessas premissas, elaborou-se um modelo conceitual do referido módulo, apresentado na Figura 5, a seguir.

Com base nesse modelo conceitual, o módulo genérico de simulação proposto neste trabalho foi construído. O módulo e sua interface para ingresso dos dados no software de simulação são apresentados na Figura 6.

Figura 5 - Modelo conceitual do módulo genérico de simulação proposto

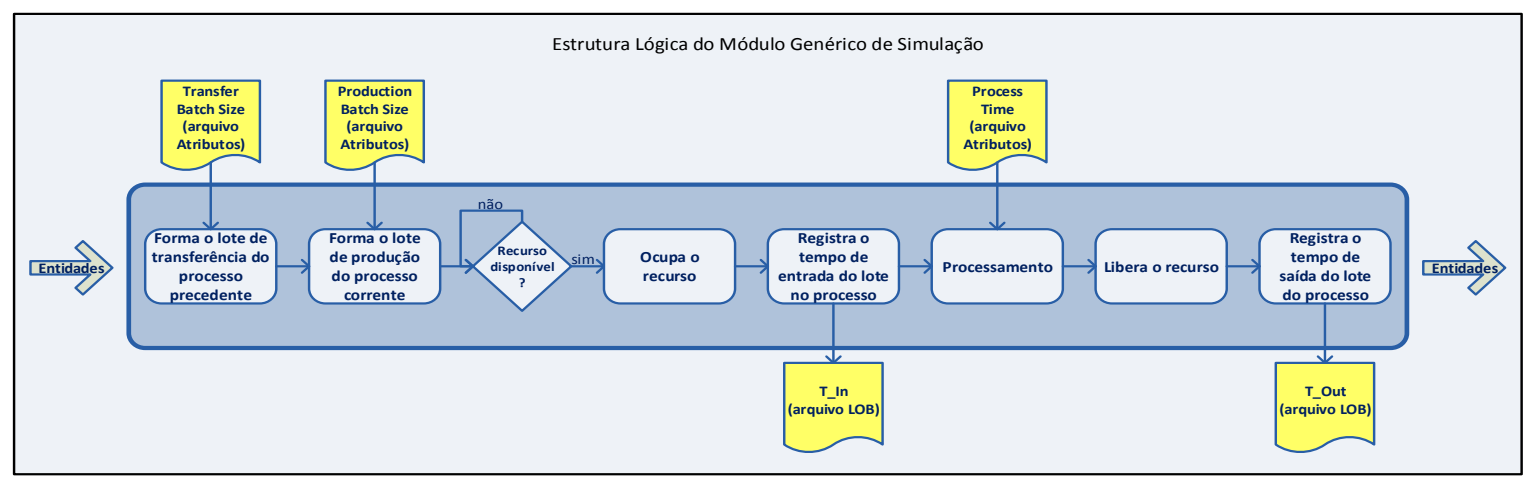


Figura 6 - Módulo genérico como visualizado no modelo de simulação (esquerda) e sua interface com o usuário para o ingresso de dados (direita)

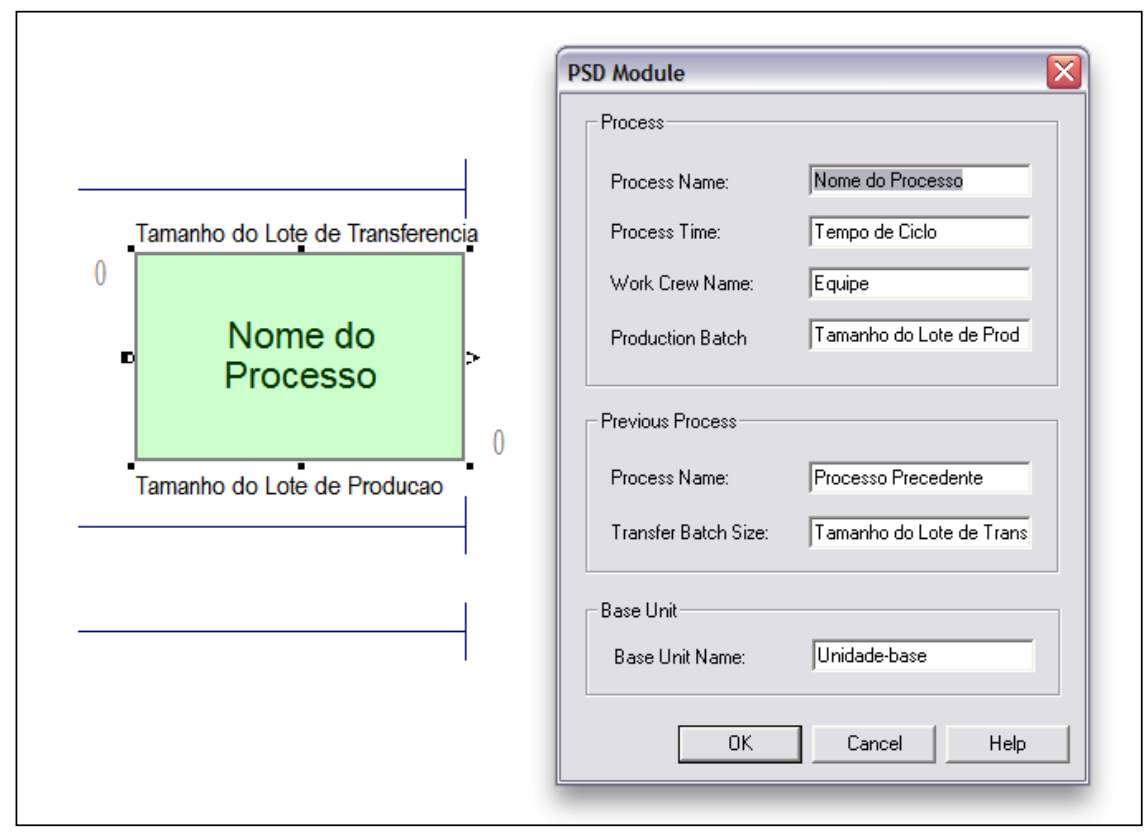

Com exceção dos campos de designação dos processos correntes, processos precedentes e unidade-base, todos os dados dos demais campos podem ser inseridos através da interface com uma planilha eletrônica. Já os dados coletados no módulo genérico (tempos de início e conclusão do processamento de cada entidade) podem ser escritos diretamente em uma planilha eletrônica, com base na qual diversas ferramentas podem ser geradas, como a linha de balanço, o gráfico de avanço físico e a curva de agregação de recursos (utilizadas no decorrer dos estudos de caso deste trabalho).

Dessa forma, o módulo genérico proposto foi utilizado na construção de todos os modelos desenvolvidos, complementando as funções dos componentes originais disponíveis no software de simulação. Esse módulo representava um processo produtivo e condensava suas características básicas, como já discutido.

A segunda forma de reutilização empregada neste trabalho foi a do próprio modelo de simulação, o que ocorreu efetivamente no estudo EC2.

Nesse estudo, procedeu-se à reutilização do modelo desenvolvido inicialmente para o empreendimento X1 (EC1), o que representou uma forma intermediária de reutilização. Embora o procedimento tenha ocorrido dentro de uma mesma organização, seu emprego se deu em empreendimentos distintos, mas que guardavam características construtivas similares. Para tanto, foram necessárias algumas pequenas adaptações no modelo originalmente proposto - que consumiram $6 \mathrm{~h}$ para sua consecução - para que pudesse ser reutilizado.

Nesse caso, o processo de modelagem caracterizou-se pela repetitividade, e os modelos, similares em vários aspectos, apresentaram somente pequenas diferenças, o que reduziu em muito o esforço de modelagem.

Contudo, é importante salientar que o elemento fundamental que permitiu a utilização dessa estratégia foi a manutenção de uma sequência de execução da unidade-base comum aos dois empreendimentos, corroborando o que apontam Mukkamala, Smith e Valenzuela (2003).

Embora não representasse uma estratégia inicial dos estudos, foi também empregada uma abordagem de modelagem conhecida como abordagem hierárquica. Segundo Oses, Pidd e Brooks (2004), nessa abordagem primeiramente são especificadas as partes principais da estrutura e seus relacionamentos sem se importar com detalhes particulares. Posteriormente, cada parte pode então ser decomposta em suas partes constituintes.

Assim, no estudo EC2 o processo de execução de fundações, que até então era modelado de forma agregada, foi decomposto em seus subprocessos com o objetivo de avaliar a utilização dos recursos produtivos. Esse componente, por sua vez, poderia vir a ser utilizado em outros modelos da empresa, ou de outras empresas que utilizassem a mesma sequência construtiva para o referido processo. 


\section{Dificuldades de implementação da simulação de eventos discretos no PSP}

Neste trabalho foram enfrentadas algumas dificuldades com relação ao uso da simulação de eventos discretos.

A primeira dificuldade enfrentada para sua utilização na elaboração do PSP diz respeito à existência de duas pressões contrárias, agindo sobre a definição do momento de início do PSP. Uma pressão refere-se à percepção dos benefícios da antecipação do PSP em relação ao momento de início do empreendimento, como uma forma de dispor de um período maior para sua consecução.

A outra pressão, no sentido contrário, é impulsionada pelo nível de incerteza existente, com vistas a protelar o início do processo na tentativa de reduzir a incerteza, o que pode gerar a necessidade de maior número de revisões das decisões tomadas ao longo do processo.

Sob essas pressões, o PSP pode ser utilizado para provocar as decisões relacionadas ao empreendimento; dessa forma, à medida que se avança no processo de elaboração, há a necessidade de definir certos aspectos sob pena de paralisar o processo ou de ser forçado a revisá-los posteriormente. Entretanto, algumas dessas decisões podem não estar ao alcance dos participantes do processo, como no caso de decisões estratégicas no nível da empresa, como a contratação de certo fornecedor ou as datas de entrega das principais etapas do empreendimento.

O processo de modelagem e simulação, em função do esforço e tempo de desenvolvimento requeridos, carece dessas definições com maior antecedência, a fim de permitir seu uso durante o PSP.

A segunda dificuldade, a complexidade de alguns modelos, já foi discutida anteriormente. No estudo EC4, o tempo de desenvolvimento do modelo foi o maior entre todos os modelos desenvolvidos. Essa complexidade deveu-se à configuração do empreendimento (número de blocos; frentes de trabalho simultâneas) e à estratégia de ataque prevista para o empreendimento, potencializado pelo nível de detalhamento adotado nos modelos construídos. Portanto, deve-se considerar o tempo disponível para o desenvolvimento e uso do modelo de simulação, quando da definição do nível de detalhe a ser adotado. Uma alternativa é o emprego de uma estratégia de modelagem hierárquica (OSES; PIDD; BROOKS, 2004), na qual o nível de detalhamento do modelo aumenta gradativamente, à medida que um maior número de informações é disponibilizado ou os envolvidos demandam tal detalhamento.

Uma terceira dificuldade pode ser atribuída à tendência dos participantes em subestimar a variabilidade dos processos produtivos e seus efeitos. Aliada a essa característica estava a ausência de dados históricos nas empresas analisadas quanto aos índices de produtividade das equipes de produção nos diferentes processos produtivos, que poderiam subsidiar o estabelecimento de durações estocásticas aos processos modelados.

Isso ficou evidenciado nos estudos EC3 e EC4, nos quais os gerentes de produção estimavam subjetivamente (com base na experiência) a duração mais provável para os processos sob análise e após simplesmente subtraiam ou somavam um dia para determinar o tempo mais pessimista e o mais otimista.

\section{Avaliação do modelo de elaboração do PSP}

\section{Aderência ao escopo de decisões}

Em todos os estudos realizados a sequência de decisões prescritas no modelo desenvolvido (SCHRAMM, 2004) foi seguida, mostrando-se adequada a sua consecução. Entretanto, percebeuse nos estudos de caso que algumas decisões receberam maior ênfase durante o processo de elaboração do PSP. Com base no número de reuniões realizadas e no número de horas despendidas em cada etapa do processo (resumidos no Quadro 4, a seguir), pode-se avaliar a maior ou a menor dedicação das equipes dos empreendimentos a alguma ou algumas decisões, em particular.

No EC1, por exemplo, houve maior esforço nas decisões relativas à unidade-base do empreendimento, em função da implementação de uma estratégia de customização das unidades (necessidade de estabelecer uma sequência de execução padronizada), enquanto no EC2, realizado na sequência e com a participação da mesma equipe da empresa $X$, a ênfase recaiu sobre a etapa de estudo dos fluxos de trabalho no empreendimento. Nesse caso, percebeu-se que o foco passou a ser um aprofundamento no entendimento dos impactos de decisões relacionadas ao dimensionamento dos recursos de produção (número de equipes) sobre os fluxos de trabalho e sobre o lead time do empreendimento. 
Quadro 4 - Quadro-resumo do esforço despendido para a realização das etapas do PSP nos estudos de caso (EC)

\begin{tabular}{|c|c|c|c|c|c|}
\hline \multirow[t]{2}{*}{ Unidade de análise } & \multirow[t]{2}{*}{ Etapas do PSP } & \multicolumn{4}{|c|}{$\begin{array}{l}\text { Número de reuniões } \\
\text { realizadas }\end{array}$} \\
\hline & & EC1 & EC2 & EC3 & EC4 \\
\hline \multirow{3}{*}{ Unidade-base } & $\begin{array}{l}\text { - Definição da sequência de execução da } \\
\text { unidade-base }\end{array}$ & \multirow{3}{*}{14} & \multirow{2}{*}{02} & \multirow{2}{*}{04} & \multirow{2}{*}{03} \\
\hline & $\begin{array}{l}\text { - Pré-dimensionamento da capacidade dos } \\
\text { recursos de produção }\end{array}$ & & & & \\
\hline & - Estudo dos fluxos de trabalho na unidade-base & & - & $\mathbf{0}$ & 03 \\
\hline \multirow{4}{*}{ Empreendimento } & $\begin{array}{l}\text { - Definição da estratégia de ataque do } \\
\text { empreendimento }\end{array}$ & 02 & 01 & 01 & 02 \\
\hline & $\begin{array}{l}\text { - Estudo dos fluxos de trabalho no } \\
\text { empreendimento }\end{array}$ & \multirow{2}{*}{10} & \multirow{2}{*}{08} & \multirow{2}{*}{09} & \multirow{2}{*}{08} \\
\hline & $\begin{array}{l}\text { - Dimensionamento da capacidade dos recursos } \\
\text { de produção }\end{array}$ & & & & \\
\hline & - Identificação e projeto de processos críticos & - & - & 01 & 02 \\
\hline \multirow{2}{*}{ Simulação } & - Reuniões de discussão dos resultados & $\nabla$ & $>$ & 04 & $\nabla$ \\
\hline & - Desenvolvimento do modelo (horas) & 80 & 06 & 40 & 126 \\
\hline \multirow{3}{*}{ Esforço total } & Número total de reuniões & 26 & 11 & 19 & 18 \\
\hline & Total de horas despendidas em reuniões & 52 & 22 & 38 & 36 \\
\hline & Duração do estudo (em meses) & 14 & 06 & 08 & 08 \\
\hline
\end{tabular}

Nota: Legenda:

- Etapa não realizada (mesma unidade-base do estudo anterior);

- Etapa realizada em conjunto com o estudo dos fluxos de trabalho no empreendimento; e

- Reuniões de discussão dos resultados da simulação inseridas no processo de elaboração do PSP.

Com relação à definição da estratégia de execução do empreendimento, percebeu-se que sua consecução pode estar condicionada a decisões anteriores ao PSP, como o plano de vendas, ficando relegada apenas a uma formalização dele.

Já com relação aos estudos EC3 e EC4, ambos realizados na empresa $\mathrm{Y}$, a maior ênfase também foi dada à etapa de estudo dos fluxos de trabalho do empreendimento. Observou-se ao longo dos estudos uma supervalorização da linha de balanço (ferramenta utilizada nesta etapa) por parte da equipe da empresa.

Outras decisões, como o estudo dos fluxos de trabalho na unidade-base passam a ter maior importância em função da tipologia de empreendimento estudado. Nos estudos EC1, EC2 e EC3, nos quais a tipologia era a de casas assobradadas, essa etapa foi elaborada concomitantemente à definição da sequência de execução da unidade-base ou ao estudo dos fluxos de trabalho do empreendimento.

No caso do estudo EC4, no qual a tipologia era de blocos de edifícios, o estudo dos fluxos de trabalho nessas unidades-base torna-se muito relevante, uma vez que a abertura de frentes de trabalho está condicionada à execução dos diversos pavimentos que formam cada bloco.
Com relação à identificação e projeto de processos críticos, essa etapa só foi desenvolvida nos estudos EC3 e EC4. No caso dos estudos EC1 e EC2, o fato de que a equipe da empresa já vinha executando empreendimentos similares àqueles fez com que tal etapa não fosse executada. No caso dos empreendimentos Y1 e Y2, por sua vez, foram discutidas algumas decisões necessárias à operacionalização daqueles processos considerados críticos, em ambos os casos elevação de alvenaria e montagem de lajes pré-fabricadas.

\section{Extensão do processo e esforço para a elaboração do PSP}

De acordo com Schramm, Costa e Formoso (2006), o esforço necessário para a elaboração do PSP é pequeno, em torno de 12 a $16 \mathrm{~h}$ para sua consecução (considerando tanto reuniões como a elaboração de preparação de ferramentas). Contudo, nos estudos realizados a carga horária despendida foi bastante superior a esse número (de 11 a 26 reuniões que demandaram de 22 a $52 \mathrm{~h}$ exclusivamente nessa atividade). Além disso, todos os estudos estenderam-se por um prazo bastante elevado (de 6 a 14 meses), e nos estudos EC1 e EC3 parte do processo de elaboração do PSP foi realizadao concomitantemente à fase de execução desses empreendimentos. Com relação

176 Schramm, F. K.; Formoso, C. T. 
ao tempo despendido em reuniões, cada estudo teve algumas peculiaridades.

No estudo EC1 foram realizadas discussões para implementação de uma abordagem de customização das unidades habitacionais. A inserção da simulação de eventos discretos ao longo do estudo também contribuiu para que o número de reuniões necessárias fosse maior. Mesmo sendo iniciado cerca de 45 dias antes da fase de execução, só foi possível empregar algumas decisões do PSP na segunda fase do empreendimento.

$\mathrm{O}$ estudo EC2 foi o estudo com o menor número de reuniões (11), mas não o estudo com a menor extensão (6 meses) entre os realizados. Esse estudo caracterizou-se pela reutilização do modelo de simulação desenvolvido no primeiro estudo, concentrando-se na discussão de inúmeros cenários, em sua maioria relacionados a diferentes alternativas relacionada ao número de equipes de produção disponíveis no canteiro.

No estudo EC3, por sua vez, a utilização da simulação ocorreu após a conclusão da fase determinística do estudo. Ao todo foram necessárias 19 reuniões para o desenvolvimento do estudo, que se estendeu por 8 meses. Entretanto, se considerada apenas a fase determinística dele, ela foi desenvolvida em 15 reuniões, num período de 4 meses.

Já o estudo EC4 foi desenvolvido em 18 reuniões, que se estenderam também por 8 meses. Nesse estudo o emprego do primeiro modelo de simulação integrou-se ao processo de elaboração do PSP em seu início. Entretanto, o segundo modelo foi desenvolvido próximo ao final do estudo, o que aumentou sua extensão em cerca de 1 mês.

Com base nessas evidências, percebe-se que nos três estudos nos quais foram desenvolvidos modelos de simulação (estudos EC1, EC3 e EC4), houve aumento na extensão do processo. $\mathrm{O}$ estudo EC2, no qual houve a reutilização do modelo, foi o estudo com a menor extensão (6 meses) e foi concluído com o menor número de reuniões (11).

\section{Funções e produtos do PSP}

O processo de elaboração do PSP, como proposto neste trabalho, em seu papel mais básico promove discussões e questionamentos acerca das características do sistema de produção do empreendimento. As reuniões de elaboração representaram um momento de focalização, discussão e experimentação para os envolvidos, tanto da empresa como de fornecedores e subempreiteiros. Além disso, a adoção do modelo de elaboração estabelece um roteiro sistemático para as discussões, determinando objetivos a serem perseguidos em termos de decisões e subprodutos ao longo do processo, ordenando-o. De fato, houve grande aderência em todos os estudos à sequência de decisões propostas.

O PSP também incentiva a adoção de uma visão sistêmica, uma vez que as decisões tomadas têm seus impactos avaliados considerando o sistema de produção como um todo. Isso foi possível através das ferramentas adotadas - linha de balanço, modelos de simulação -, bem como pela participação de vários atores do sistema de produção - engenheiro de planejamento, fornecedores de materiais e sistemas construtivos e subempreiteiros.

O PSP formaliza e registra decisões. Embora muitas das decisões tomadas ao longo da elaboração do PSP não sejam novidade para os envolvidos, muitas vezes elas não são adequadamente formalizadas. Dessa forma, o processo de elaboração do PSP prevê que todas as decisões tomadas sejam formalmente registradas e que, ao final do processo, um relatório seja elaborado e utilizado para embasar tanto as decisões ao longo da fase de execução como a elaboração do PSP de futuros empreendimentos.

Após concluído, o PSP estabelece um estado futuro a ser alcançado. Um plano de longo prazo pode ser considerado como o produto final do PSP. Entretanto, além de um conjunto de datas-marco a serem atingidas, esse plano condensa uma série de diretrizes acerca de como o sistema de produção deve ser organizado para a consecução dessas datas-marco, ou como os recursos devem ser gerenciados para produzir o produto final.

\section{Modelo de elaboração do PSP utilizando simulação de eventos discretos}

Com base nas evidências dos estudos de caso realizados, propôs-se um modelo de elaboração do PSP utilizando SED como ferramenta de apoio à tomada de decisão. Esse modelo (Figura 6) é resultado de um refinamento e expansão do modelo proposto em Schramm (2004). Cabe destacar entretanto que, conforme descrito anteriormente, esse modelo não foi formalmente aplicado em nenhum dos estudos de caso desenvolvidos, e sua elaboração baseou-se no somatório das evidências oriundas dos quatro estudos realizados.

Buscando estabelecer uma estratégia para o emprego da SED como uma ferramenta de apoio à 
tomada de decisão no PSP, propõe-se dividir a elaboração do PSP em duas fases: uma fase determinística, que consiste na sequência de decisões do modelo de PSP; e uma fase dinâmica, ${ }^{3}$ que corresponde ao desenvolvimento e emprego do modelo de simulação. É importante ressaltar que, embora distintas, essas fases não são estanques, sobrepondo-se.

A fase determinística (porção superior da Figura 7, em azul) consiste no mesmo escopo e sequência de decisões, agrupadas em decisões relativas à unidade-base e ao empreendimento, preconizado no modelo anterior (SCHRAMM, 2004).

Preferiu-se explicitar - além da definição da sequência de execução e do pré-dimensionamento da capacidade dos recursos de produção - outras duas decisões: o dimensionamento dos lotes de produção e transferência; e a definição preliminar dos ritmos dos processos produtivos, que são informações relevantes para o desenvolvimento do modelo de simulação. Os fluxos de decisão e revisão, representados por setas em sentidos opostos, ressaltam o papel sistêmico do processo de tomada de decisão, uma vez que existe grande interdependência entre as decisões. Parte das informações necessárias para o desenvolvimento dos modelos originaram-se dos dados disponíveis das primeiras seis decisões da fase determinística.

Deve-se ressaltar a importância do amadurecimento das definições dessa etapa, uma vez que suas modificações impactam muito fortemente na estrutura dos modelos de simulação, podendo, em alguns casos extremos, gerar a necessidade de reconstrução parcial ou total deste, como no primeiro estudo de caso.

Figura 7 - Modelo de elaboração do PSP com o uso de simulação de eventos discretos

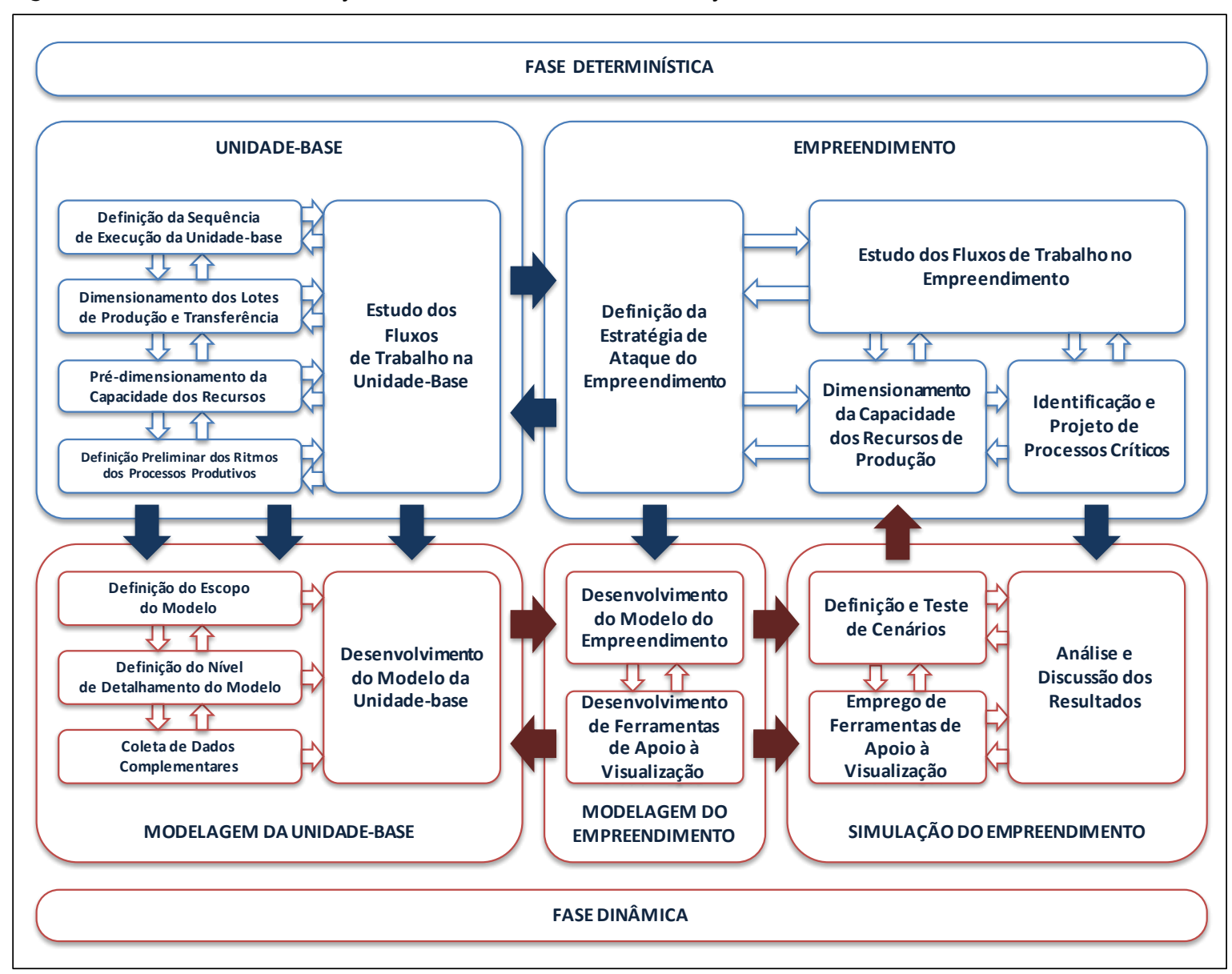

${ }^{3}$ O emprego do termo "dinâmico" em vez de "estocástico" ocorre uma vez que os maiores benefícios oriundos do emprego da simulação dizem respeito ao processo de modelagem em si e à compreensão das interações dinâmicas entre processos e recursos produtivos. 
A fase dinâmica (porção inferior da Figura 7, em vermelho) foi dividida em três etapas básicas:

(a) modelagem da unidade-base;

(b) a modelagem do empreendimento; e

(c) simulação do empreendimento.

$\mathrm{Na}$ etapa de modelagem da unidade-base deve-se definir o escopo do modelo a ser desenvolvido, se abrangerá todo o empreendimento (como realizado em todos os estudos de caso) ou uma parte do sistema de produção.

Após, deve-se definir o nível de detalhamento do modelo, que se relaciona diretamente ao detalhamento da sequência de execução da unidade-base do empreendimento. Dessa forma, deve-se analisar a necessidade de que façam parte do modelo todos os processos, ou se é possível condensá-los em etapas maiores, como, por exemplo, etapa de estrutura ou etapa de acabamentos. Outra possibilidade é o desenvolvimento de um modelo mais simples, com etapas condensadas, e detalhando-o gradativamente, conhecido como abordagem hierárquica (OSES; PIDD; BROOKS, 2004).

$\mathrm{Na}$ etapa a modelagem do empreendimento definese o número de modelos ou submodelos necessários para representar o sistema de produção do empreendimento, com base na definição da estratégia de execução. Assim, o número de frentes de trabalho simultaneamente executadas determina o número de submodelos (quando considerados dentro de um único modelo) ou modelos (quando considerados separadamente) necessários.

Juntamente à modelagem do empreendimento, pode-se desenvolver ferramentas de visualização que facilitem o entendimento e a avaliação dos cenários a ser simulados. Nos estudos realizados utilizou-se a linha de balanço com essa finalidade, entretanto outras técnicas podem ser empregadas.

Já a simulação do empreendimento, terceira etapa da fase dinâmica, consiste na definição e teste dos cenários, do emprego das ferramentas de visualização para apoiar a análise e discussão dos resultados. Esses, por sua vez, são utilizados para avaliar decisões no nível do empreendimento, como a estratégia de ataque, o estudo dos fluxos de trabalho e o dimensionamento da capacidade dos recursos de produção. Deve-se destacar também o papel de apoio à programação da produção desempenhado pelo modelo de simulação, a partir do desdobramento das decisões do PSP. Pode-se ainda simular processos críticos, como no estudo EC4.

\section{Estágios de implementação da simulação de eventos discretos no PSP}

Com base nas evidências coletadas ao longo dos estudos, propõem-se algumas condições mínimas para o emprego da SED como uma ferramenta do PSP, agrupadas para três estágios de implementação pelos quais a empresa poderia passar.

Esses estágios estão relacionados ao nível de maturidade da empresa com a prática da elaboração do PSP e ao domínio da tipologia do empreendimento a ser executado. Ressalta-se, entretanto, que os estágios aqui descritos têm caráter propositivo e baseiam-se nas características das empresas que fizeram parte dos estudos de caso. O Quadro 5, a seguir, resume as principais características e recomendações para a implementação do PSP e da SED nos três estágios propostos.

\section{Conclusões e recomendações}

Um modelo para a elaboração do PSP com o emprego da simulação de eventos discretos como ferramenta de apoio à tomada de decisão foi proposto. Esse modelo tomou como base o modelo proposto por Schramm (2004) no que concerne às decisões que formaram uma fase determinística do PSP, propondo a adição de uma fase dinâmica, na qual outros aspectos são considerados a partir do emprego da SED.

Percebeu-se que o emprego da SED como ferramenta do PSP não foi igual em todos os estudos realizados. Com base nas diferenças entre a importância dada pelas diferentes equipes de planejamento que tomaram parte nos estudos, propõe-se que a implementação do PSP deva ocorrer em estágios que coincidam com seu nível de consolidação como uma prática gerencial da empresa e que o emprego da simulação tenha seus maiores benefícios para empresas que se encontrem em um estágio mais avançado de implementação do PSP e que detêm certo domínio sobre a tipologia e tecnologias construtivas empregadas no empreendimento.

De uma forma geral, o emprego da SED permitiu o teste de diferentes cenários ao longo dos estudos. Esses cenários consistiram de alternativas na organização do sistema de produção com relação a mudanças na estratégia de ataque do empreendimento, dimensionamento da capacidade dos recursos de produção e redistribuição de processos a esses recursos. 
Quadro 5 - Estágios para a implementação da simulação no PSP em empresas construtoras

\begin{tabular}{|c|c|c|}
\hline Estágio & $\begin{array}{c}\text { Características da } \\
\text { empresa/empreendimento }\end{array}$ & Recomendações \\
\hline 1 & $\begin{array}{l}\text { - A empresa ainda não implementou o PSP } \\
\text { - A tipologia do empreendimento é nova } \\
\text { para a equipe de produção, não tendo sido } \\
\text { ainda utilizada em nenhum } \\
\text { empreendimento da empresa }\end{array}$ & $\begin{array}{l}\text { - Empregar o modelo de PSP em sua fase } \\
\text { determinística } \\
\text { - Se houver intenção de replicar a tipologia, } \\
\text { avaliar a possibilidade de desenvolver um } \\
\text { modelo de simulação } \\
\text { - Avaliar a possibilidade de utilizar a } \\
\text { simulação para o estudo de processos } \\
\text { específicos }\end{array}$ \\
\hline 2 & $\begin{array}{l}\text { - A empresa já implementou o PSP } \\
\text { - A tipologia do empreendimento já foi } \\
\text { utilizada em outros empreendimentos da } \\
\text { empresa, mas não há um PSP elaborado } \\
\text { previamente } \\
\text { - Há perspectiva de continuidade no } \\
\text { emprego da tipologia do empreendimento } \\
\text { em estudo }\end{array}$ & $\begin{array}{l}\text { - Empregar o modelo de elaboração do PSP } \\
\text { em suas fases determinística e dinâmica } \\
\text { - Enfatizar o estabelecimento de padrões para } \\
\text { a sequência construtiva das unidades-base } \\
\text { do empreendimento } \\
\text { - Construir (e utilizar, se possível) um modelo } \\
\text { de simulação com vistas à reutilização }\end{array}$ \\
\hline 3 & $\begin{array}{l}\text { - A empresa já tem consolidado o PSP } \\
\text { - A tipologia do empreendimento já foi } \\
\text { utilizada ou tem muitas características } \\
\text { comuns a empreendimentos anteriores para } \\
\text { os quais o PSP foi elaborado } \\
\text { - Um modelo de simulação reutilizável já foi } \\
\text { construído e testado em empreendimento } \\
\text { anterior }\end{array}$ & $\begin{array}{l}\text { - Revisar e adaptar as decisões do PSP na fase } \\
\text { determinística ao novo empreendimento } \\
\text { - Avaliar e adaptar o modelo de simulação } \\
\text { construído } \\
\text { - Empregar o modelo de elaboração do PSP } \\
\text { em sua fase dinâmica, procurando explorar } \\
\text { os efeitos de mudanças mais pontuais no } \\
\text { sistema de produção (regulagem fina) }\end{array}$ \\
\hline
\end{tabular}

Verificou-se que o emprego de ferramentas que melhoram a visualização dos resultados da simulação pode trazer inúmeros benefícios ao processo. Propôs-se a integração da linha de balanço como uma ferramenta de apoio à visualização dos resultados da simulação, valorizando a análise dos resultados não apenas sob o ponto de vista das atividades de transformação, mas, sobretudo, das atividades de fluxo.

Quanto ao nível de detalhamento dos modelos, esta pesquisa indicou que modelos mais simples permitem demonstrar os efeitos da aplicação de conceitos de gestão da produção mais diretamente. Modelos mais detalhados, por sua vez, permitem avaliar os efeitos sistêmicos das decisões simuladas, possibilitando a avaliação e a comparação dos efeitos dessas mudanças com as experiências práticas dos envolvidos, aumentando a credibilidade do modelo.

Entretanto, o excesso de detalhamento mostrou-se como um dos principais motivos para algumas das dificuldades enfrentadas no trabalho: tempo e esforço excessivos para o desenvolvimento e emprego dos modelos de simulação, além de impacto reduzido do emprego das ferramentas de visualização dos resultados do modelo.

Em função do elevado tempo de desenvolvimento de modelos, propôs-se o emprego de duas estratégias: a construção de componentes (módulos) genéricos; e a reutilização dos próprios modelos de simulação. Essas estratégias mostraram-se extremamente relevantes na consecução de seus objetivos, permitindo efetivamente redução do tempo de desenvolvimento dos modelos de simulação e seu emprego mais precoce na elaboração do PSP dos empreendimentos estudados.

Por se tratar de uma pesquisa construtiva, a contribuição teórica deste trabalho ao avanço do conhecimento diz respeito ao refinamento do modelo de elaboração do PSP na construção civil, atividade gerencial ainda pouco explorada na prática do setor. Ainda, mas não dissociada da primeira contribuição, houve a melhor compreensão acerca dos benefícios e dificuldades do emprego da SED e sua aplicabilidade como uma ferramenta do PSP.

Do ponto de vista prático, considera-se que este trabalho não só se constitui em uma contribuição para as empresas que participaram dos estudos 
como também pode ser adaptado ao contexto específico de outras empresas e empreendimentos.

Como sugestões para futuros trabalhos, tendo em vista os resultados da pesquisa, entende-se que seja oportuno:

(a) uma avaliação e refinamento do modelo proposto, a partir de sua aplicação em outros tipos de empreendimentos e contextos;

(b) estudos que visem propor diretrizes para o alinhamento do PSP aos objetivos estratégicos da produção, bem como avaliar a possibilidade do emprego dos modelos de simulação de eventos discretos no apoio à tomada de decisão em nível mais estratégico; e

(c) avaliar a exequibilidade do emprego de uma estratégia de modelagem hierárquica, como forma de lidar com o maior nível de incerteza no período que antecede o início da fase de execução do empreendimento, quando o PSP dever ser iniciado.

\section{Referências}

ALVES, T. C. L.; TOMMELEIN, I. D.; BALLARD, G. Simulation as a Tool for Production System Design in Construction. In: ANNUAL CONFERENCE OF THE INTERNATIONAL GROUP FOR LEAN CONSTRUCTION, 14., Santiago do Chile, 2006. Proceedings... Santiago do Chile: IGLC, 2006.

BALLARD, G. et al. Production System Design in Construction. In: ANNUAL CONFERENCE OF THE INTERNATIONAL GROUP FOR LEAN CONSTRUCTION, 9., Singapore, 2001. Proceedings... Singapore: IGLC, 2001.

BELTON, V.; ELDER, M. Decision Support Systems: learning from visual interactive modeling. Decision Supporting Systems. v. 12, n. 4-5, p. 355-364, 1991.

DRAPER, J. D.; MARTINEZ, J. The Evaluation of Alternative Production System Designs with Discrete Event Simulation. In: ANNUAL CONFERENCE OF THE INTERNATIONAL GROUP FOR LEAN CONSTRUCTION, 10., Gramado, 2002. Proceedings... Gramado: IGLC/UFRGS, 2002.

GIDADO, K. I. Project Complexity: the focal point of constriction production planning.

Construction Management and Economics, v. 14, p. 213-225, 1996.

HAJJAR, D.; ABOURIZK, S. M. Unified Modeling Methodology for Construction Simulation. Journal of Construction Engineering and Management, v. 128, n. 2, p. 174-185, Apr. 2002.
HAPIN, D. H.; WOODHEAD, R. W. Design of Construction and Process Operations. [s.1.]: John Wiley \& Sons, 1976.

HONG, Z.; SHI, J. J.; TAM, C. M. Visual Modeling and Simulation for Construction Operations. Automation in Construction. v. 11, n. 1, p. 47-57, 2002.

HOWELL, G.; BALLARD, G. Design of Construction Operations. LCI White Paper 04. Portland: Lean Construction Institute, 1999. Disponível em:

<http://www.leanconstruction.org >. Acesso em: 21 nov. 2005.

HURRION, R. D. The Design, Use and Required Facilities of an Interactive Visual Computer Simulation Language to Explore Production Planning Problems. 1976. PhD Thesis University of London, 1976.

KELTON, W. D.; SADOWSKI, R. P.; STURROCK, D. T. Simulation with Arena. $3^{\text {rd }}$ ed. New York: McGraw-Hill, 2004.

KOSKELA, L. An Exploration Towards a Production Theory and its Application to Construction. 2000. Ph.D. Thesis - Technical Research Centre of Finland, Espoo, 2000.

KOSKELA, L. On New Footnotes to Shingo. In: ANNUAL CONFERENCE OF THE INTERNATIONAL GROUP FOR LEAN CONSTRUCTION, 9., Singapore, 2001. Proceedings... Singapore: IGLC, 2001.

LUKKA, K. The Constructive Research Approach. In: OCALA, L.; HILMOLA, O.-P. (Eds.). Case Study Research in Logistics. Turku: Turku School of Economics and Business Administration, 2003. Series B1. P. 83-101.

MACKULAK, G. T.; LAWREWNCE, F. P.; COLVIN, T. Effective Simulation Model Reuse: a case study for AMHS modeling. In: WINTER SIMULATION CONFERENCE, Washington, 1998. Proceedings... Washington: WSC, 1998.

MENDES JUNIOR, R.; HEINECK, L. F. M. Preplanning Method for Multi-Story Building Construction Using Line of Balance. In: ANNUAL CONFERENCE OF THE INTERNATIONAL GROUP FOR LEAN CONSTRUCTION, 6., Guarujá, 1998. Proceedings... Guarujá: IGLC/UFRGS, 1998.

MUKKAMALA; P. S.; SMITH, J. S.; VALENZUELA, J. F. Designing Reusable Simulation Modules for Electronics Manufacturing Systems. In: WINTER SIMULATION CONFERENCE, 2003, New Orleans.

Proceedings... New Orleans: WSC, 2003. 
NASEREDDIN, M.; MULLENS, M. A.; COPE, D. Automated Simulator Development: a strategy for modeling modular housing production.

Automation in Construction, v. 16, p. 212-223, 2007.

OLOUFA, A. A.; IKEDA, M.; NGUYEN, T. Resource-Based Simulation Libraries for Construction. Automation in Construction, v. 7, p. 315-326, 1998.

OSES, N.; PIDD, M.; BROOKS, R. J. Critical Issues in the Development of Component-Based Discrete Simulation. Simulation Modelling Practice and Theory, v. 12, p. 495-514, 2004.

ROBINSON, S. Simulation: the practice of model development and use. Chichester: John Wiley \& Sons, 2003.

RODRIGUES, A. A. O Projeto do Sistema de Produção no Contexto de Obras Complexas. Porto Alegre, 2006. Dissertação (Mestrado em Engenharia Civil) - Programa de Pós-Graduação em Engenharia Civil, Universidade Federal do Rio Grande do Sul, Porto Alegre, 2006.

SAFFARO, F. A.; PAULA, E. C. P. Formulating the Work Flow Plan for Horizontal Projects: case study. In: ANNUAL CONFERENCE OF THE INTERNATIONAL GROUP FOR LEAN CONSTRUCTION, 10., Gramado, 2002. Proceedings... Gramado: IGLC/UFRGS, 2002.

SANTOS, R. B. Avaliação da Aplicação da Teoria das Restrições no Processo de Planejamento e Controle da Produção de Obras de Edificação. Porto Alegre, 2001. Dissertação (Mestrado em Engenharia Civil) - Programa de Pós-graduação em Engenharia Civil, Universidade Federal do Rio Grande do Sul, Porto Alegre, 2001.
SCHRAMM, F. K. O Projeto do Sistema de Produção na Gestão de Empreendimentos Habitacionais de Interesse Social. Porto Alegre, 2004. Dissertação (Mestrado em Engenharia Civil) - Programa de Pós-Graduação em Engenharia Civil, Universidade Federal do Rio Grande do Sul, Porto Alegre, 2004.

SCHRAMM, F. K.; COSTA, D. B.; FORMOSO, C. T. O Projeto do Sistema de Produção na Gestão de Empreendimentos Habitacionais de Interesse Social. Ambiente Construído, Porto Alegre, v. 6, n. 2, p. 59-74, abr./jun. 2006.

SHI, J. J.; ABOURIZK, S. M. An Automated Modeling System for Simulating Earthmoving Operations. Computer-Aided Civil and Infrastructure Engineering, v. 13, p. 121-130, 1998.

SHI, J. J.; ABOURIZK, S. M. Resource-Based Modeling for Construction Simulation. Journal of Construction Engineering and Management, v. 123, n. 1, p. 26-33, mar. 1997.

SHI, J. J.; ZHANG, H. Iconic Animation of Construction Simulation. In: WINTER SIMULATION CONFERENCE, Phoenix, 1999. Proceedings... Phoenix: WSC, 1999.

\section{Agradecimentos}

Os autores agradecem à Capes, pela concessão de bolsas de estudos, e à Fapergs, pelo auxílio financeiro, através do edital Proade3, que possibilitou a aquisição de equipamentos e softwares utilizados neste trabalho.

Fábio Kellermann Schramm

Programa de Pós-Graduação em Arquitetura e Urbanismo | Universidade Federal de Pelotas | Rua Benjamin Constant, 1359, Centro | Pelotas - RS - Brasil | CEP 96010-020 | Tel.: (53) 3284-5500 | E-mail: fabioks@ufpel.edu.br

\section{Carlos Torres Formoso}

Núcleo Orientado para a Inovação da Edificação, Programa de Pós-raduação em Engenharia Civil | Universidade Federal do Rio Grande do Sul | Av. Osvaldo Aranha, 99, $3^{\circ}$ andar, Bom Fim | Porto Alegre - RS - Brasil | CEP 90035-190 | Tel.: (51) 3308-3518 |

E-mail: formoso@ufrgs.br

Revista Ambiente Construído

Associação Nacional de Tecnologia do Ambiente Construído

Av. Osvaldo Aranha, $99-3^{\circ}$ andar, Centro Porto Alegre - RS - Brasil

CEP 90035-190

Telefone: +55 (51) 3308-4084

Fax: +55 (51) 3308-4054

www.seer.ufrgs.br/ambienteconstruido

E-mail: ambienteconstruido@ufrgs.br 